\title{
Kompetensi Supervisor dalam Supervisi Guru Bimbingan Konseling (Suatu Tinjauan Studi Pustaka)
}

\author{
Aulia Ilfana*, Happy Karlina Marjo \\ Prodi Studi Magister Bimbingan dan Konseling, Fakultas Ilmu Pendidikan \\ Universitas Negeri Jakarta \\ *Corresponding Author. Email: auliailfana_1108820007@mhs.unj.ac.id
}

\begin{abstract}
This study aims to describe the competence of supervisors in the supervision of counseling guidance teachers. This research method uses a literature study which contains the concepts and theories used based on the available literature, especially from articles published in various scientific journals. Furthermore, the data analysis technique used interpretive descriptive analysis. The results of this study indicate that the supervision of guidance and counseling teachers is proven to be effective in increasing the skills, understanding of counseling teachers and able to increase the mastery of counseling practice. Where with the implementation of counseling guidance supervision carried out by supervisors, it can help counseling guidance teachers to improve and further develop skills in counseling guidance service skills. The supervisory role requires many different skills and values from the therapeutic relationship. Supervisors must have the education and training to carry out their role so that counseling teachers receive regular feedback so that they have a basis on which to hone their skills.
\end{abstract}

Abstrak: Penelitian ini bertujuan untuk mendeskripsikan kompetensi supervisor dalam supervisi guru bimbingan konseling. Metode penelitian ini menggunakan studi pustaka yang berisi mengenai konsep dan teori yang digunakan berdasarkan literatur yang tersedia, terutama dari artikel-artikel yang dipublikasikan dalam berbagai jurnal ilmiah. Selanjutnya teknik analisis datanya menggunakan analisis deskriptif interpretatif. Hasil penelitian ini menunjukkan bahwa dalam supervisi guru bimbingan dan konseling terbukti efektif dapat meningkatkan keterampilan, pemahaman guru bimbingan konseling dan mampu dalam meningkatkan penguasaan praktek konseling. Dimana dengan diterapkannya supervisi bimbingan konseling yang dilakukan supervisor dapat membantu guru bimbingan konseling untuk meningkatkan dan lebih mengembangkan skill dalam keterampilan layanan bimbingan konseling. Peran pengawas membutuhkan banyak keterampilan dan nilai yang berbeda dari hubungan terapeutik. Pengawas harus memiliki pendidikan dan pelatihan untuk menjalankan peran mereka agar guru bimbingan konseling menerima umpan balik secara teratur sehingga mereka memiliki dasar untuk mengasah keterampilan mereka.

\section{Article History}

Received: $12-11-2021$

Revised: 16-12-2021

Accepted: 22-12-2021

Published: 07-01-2022

\section{Key Words:}

Supervisor Competence, Supervision, Counseling Guidance Teacher

\section{Sejarah Artikel}

Diterima: 12-11-2021

Direvisi: 16-12-2021

Disetujui: 22-12-2021

Diterbitkan: 07-01-2022

\section{Kata Kunci:}

Kompetensi Supervisor, Supervisi, Guru Bimbingan Konseling

How to Cite: Ilfana, A., \& Marjo, H. (2022). Kompetensi Supervisor Dalam Supervisi Guru Bimbingan Konseling (Suatu Tinjauan Studi Pustaka). Jurnal Paedagogy, 9(1), 192-197. doi:https://doi.org/10.33394/jp.v9i1.4534

\section{Pendahuluan}

Pendidikan adalah sesuatu yang essensial bagi manusia. Melalui pendidikan, manusia belajar menghadapi segala problematika yang ada di alam semesta demi mempertahankan kehidupannya. Pendidikan dalam kehidupan manusia mempunyai peranan yang sangat penting, pendidikan dapat membentuk kepribadian seseorang dan pendidikan diakui sebagai kekuatan yang dapat menentukan prestasi dan produktivitas seseorang. Dengan bantuan pendidikan, seseorang memahami dan menginterpretasikan lingkungan yang dihadapi, 
sehingga seseorang tersebut mampu menciptakan karya yang gemilang dalam hidupnya atau dengan kata lain manusia dapat mencapai suatu peradaban dan kebudayaan yang tinggi dengan bantuan pendidikan (Mustofa 2013).

Sehubungan dengan itu maka untuk mencapai suatu realisasi dan tujuan pendidikan nasional, memerlukan partisipasi guru sebagai warga negara dan warga masyarakat. Apalagi guru dikenal sebagai tenaga professional kependidikan, yang mempunyai tanggung jawab besar dalam menangani berhasil atau tidaknya program pendidikan dan pembangunan bangsa, sehingga secara ideal, baik atau buruknya suatu bangsa dimasa mendatang banyak terletak di tangan guru.

Guru BK memiliki tugas dan tanggung jawab yang cukup berat. Guru harus membimbing anak didik menjadi manusia pembangunan yang berpancasila, kemudian memiliki kejujuran profesional, selalu memelihara hubungan baik dengan anak didik, teman sejawat, orang tua murid atau keluarga maupun masyarakat, mengenal anak didik, disamping harus meningkatkan mutu profesi dan organisasi profesionalnya serta mematuhi ketentuanketentuan yang telah ditetapkan oleh pemerintah dibidang pendidikan (Mashadi, 2013). Dalam proses pendidikan semestinya menyentuh dunia kehidupan peserta didik secara individual. Proses ini tidak cukup hanya dilakukan oleh guru, tetapi perlu bantuan profesi pendidik lain yaitu guru bimbingan dan konseling atau konselor. Bimbingan dan konseling sebagai bagian intregral dari proses pendidikan merupakan salah satu komponen penting yang menentukan kualitas pelayanan pendidikan pada siswa (Handika \& Herdi, 2021; Sari \& Herdi, 2021),

Bimbingan dan konseling semakin hari semakin dirasakan perlu keberadaannya di setiap sekolah. Hal ini didukung oleh berbagai macam faktor, seperti dikemukakan oleh Partowisastro (1982) bahwa setelah keluarga berperan sebagai peranan utama dalam tumbuh kembang siswa, maka selanjutnya yang menempati posisi kedua adalah peranan sekolah.Setiap siswa memiliki pemikiran, sikap kepribadian yang berbeda, dan juga setiap anak mengalami perkembangan dalam berbagai aspek dalam dirinya. Maka, mereka membutuhkan bimbingan baik dalam memahami keadaan dirinya, mengarahkan dirinya, maupun dalam mengatasi berbagai macam kesulitan. Walaupun demikian, profesi bimbingan dan konseling masih dirundung banyak masalah terutama pada tataran praksisnya yang erat dengan kaitannya dengan pelayanan bimbingan dan konseling yang profesional.

Layanan bimbingan dan konseling di sekolah juga masih banyak masalah pada tataran praksisnya. Masalah-masalah internal masih menjadi bagian kendala pelaksanaan kinerja guru pembimbing atau konselor di sekolah. Penguasaan kompetensi dan keterampilan sebagai bentuk kualitas sumber daya manusia juga menjadi sentral terkendalanya kinerja guru BK di sekolah. Salah satu faktor yang mempengaruhi meningkatnya kualitas guru bimbingan konseling atau konselor yakni supervisi. Supervisi mempunyai arti pengawasan. Menurut Willes (1967) supervisi adalah bantuan untuk mengembangkan situasi belajar yang lebih baik. Sementara menurut Breghs dan Justmen, mendefinisikan bahwa supervisi adalah usaha sistematis untuk mendorong secara berkelanjutan dan mengarahkan pertumbuhan, dan pengembangan para guru agar berbuat lebih efektif dalam pencapaian tujuan pendidikan. Supervisi bimbingan dan konseling merupakan satu relasi antara supervisor dan konselor (supervisi), di mana supervisor (konselor junior) memberi dukungan dan bantuan untuk meningkatkan mutu kinerja profesional supervisi yang bertumpu pada satu prinsip, yaitu mengakui setiap manusia mempunyai potensi untuk berkembang (Amelisa, 2019).

Kenyataannya dilapangan masih perlu dibenahi dalam hal supervise pendidikan yang dilakukan oleh para pengawas. Cukup banyak para pengawas konselor dalam menjalankan 
tugasnya belum maksimal memberikan pelayanan dan bimbingan kepada guru disekolah, dikarenakan keahlian dan keterampilan pengawas tersebut masih pas-pasan, Hal inilah yang sering dikeluhkan oleh para dewan guru. Idealnya seorang pengawas harus lebih pintar dan mampu dari dalam hal pembinaan, bimbingan, pemberdayaan. Namun kenyataannya masih ada pengawas yang belum begitu terampil, meskipun ada juga yang sudah terampil hal ini masih belum memadai. Adapun tujuan penelitian ini adalah untuk mendeskripsikan kompetensi supervisor dalam supervisi guru bimbingan konseling.

\section{Metode Penelitian}

Penelitian ini dilakukan dengan cara studi pustaka yaitu berisi teori-teori yang relevan dengan masalah-masalah penelitian. Menurut Wiratna (2014) studi pustaka berisi mengenai konsep dan teori yang digunakan berdasarkan literatur yang tersedia, terutama dari artikel-artikel yang dipublikasikan dalam berbagai jurnal ilmiah. Kajian pustaka berfungsi untuk membangun konsep atau teori yang menjadi dasar studi dalam penelitian. Selanjutnya teknik analisis datanya menggunakan analisis deskriptif interpretatif.

\section{Hasil Penelitian dan Pembahasan}

British Associations for Counselling and Psychoterapy (BAC) (Wheeler \& King, 2001) menjelaskan bahwa supervisi diartikan sebagai suatu proses untuk menjaga standar konseling yang memadai dan suatu metode konsultasi dengan horizon yang lebih luas dari seorang praktisi yang berpengalaman BAC juga mendefinisikan Supervisi sebagai suatu dukungan konsultatif dan menggambarkan hubungan. Secara resmi dalam BAC Code of Ethics and Practice for Supervisors of Counsellors dirumuskan bahwa Supervisi adalah suatu proses kolaboratif yang bersifat formal dengan tujuan untuk membantu supervisee menjaga standar etika dan profesi dalam praktek konseling dan untuk mempertinggi kreativitas (BAC, dalam Wheeler \& King. 2001), antara supervisor dan konselor sebagai suatu hal yang menyediakan ruang bagi konselor untuk merefleksikan prakteknya.

Supervisi layanan bimbingan dan konseling adalah upaya untuk mendorong, mengkoordinasi dan menuntun pertumbuhan petugas binbingan dan konseling atau yang biasa disebut konselor secara berkesinambungan baik secara individu maupun kelompok agar lebih memahami dan lebih baik bertindak secara efektif dalam melaksanakan layanan bimbingan dan konseling, sehingga mereka mampu mendorong pertumbuhan setiap siswa secara berkesinambungan agar dapat berprestasi secara cerdas dan kaya dalam lingkungan masyarakat.

Program kegiatan supervisi bukan merupakan konseling/psikoterapi, pemaksaan (imposing), kritik negatif (negative criticism), memperdayakan (disempowering), pertemanan (friendship), mencari kesalahan (fault finding), hukuman (punishment), maupun untuk konselor yang baru (vovicecounselor). Tujuan yang diharapkan tercapai dalam supervisi BK di sekolah, yaitu meningkatkan kesadaran dan identitas profesional, mendorong perkembangan pribadi dan profesional, mempromosikan kinerja profesional, dan memberikan jaminan mutu terhadap praktik profesional. Namun demikian, dalam pelaksanaan supervisi BK perlu diperhatikan beberapa prinsip dasar supervisi BK, sehingga proses yang dilakukan bisa terukur dan dipertanggungjawabkan.

Tujuan dari supervisi bimbingan dan konseling mengendalikan kualitas, supervisor bertanggung jawab memonitor pelaksanaan kegiatan bimbingan konseling dan hasil-hasilnya yang berupa kehidupan dan perkembangan siswa atau konseli yang lebih baik. Maka supervisor bimbingan konseling perlu memiliki kemampuan dalam kepemimpinan, 
kemampuan dalam hubungan manusia, kemampuan dalam proses kelompok kemampuan dalam administrasi personel, kemampuan dalam bimbingan konseling dan kemampuan dalam evaluasi.

Supervisi bimbingan konseling terbukti efektif dapat meningkatkan keterampilan, pemahaman guru bimbingan konseling dan mampu dalam meningkatkan penguasaan praktek konseling. Dimana dengan diterapkannya supervisi bimbingan konseling yang dilakukan supervisor dapat membantu guru bimbingan konseling untuk meningkatkan dan lebih mengembangkan skill dalam keterampilan layanan bimbingan konseling.

Pentingnya supervisi ini juga dapat dilihat dari hasil penelitian yang dilakukan oleh (Amelisa, 2019) membuahkan hasil bahwa supervisi bimbingan konseling terbukti efektif dapat meningkatkan keterampilan, pemahaman guru bimbingan dan konseling dan mampu dalam meningkatkan penguasaan praktek konseling. Dimana dengan diterapkannya supervisi bimbingan dan konseling yang dilakukan supervisor dapat membantu guru bimbingan dan konseling untuk meningkatkan dan lebih mengembangkan skill dalam keterampilan layanan bimbingan dan konseling. Dari penelitian tersebut untuk memberikan supervisi klinis yang efektif, supervisor harus kompeten baik dalam praktik supervisi maupun dalam bidang konseling yang diawasi.

Menurut Corey, Callanan (2011) Supervisi klinis yang efektif, supervisor harus kompeten baik dalam praktik supervisi maupun dalam bidang konseling yang diawasi. Dari sudut pandang etika dan hukum, supervisor harus memiliki pendidikan dan pelatihan untuk menjalankan peran mereka secara memadai. Undang-undang lisensi konselor di sejumlah negara bagian sekarang menetapkan bahwa konselor profesional berlisensi yang mempraktikkan supervisi diharuskan memiliki pengalaman pelatihan yang relevan dan kursus kerja dalam pengawasan.

Proses pengawasan bimbingan dan konseling memerlukan personel yang memiliki kompetensi dibidang pengawasan, meliputi: kepribadian, sosial, supervisi manajerial, supervisi akademik, evaluasi pendidikan, penelitian dan pengembangan. Dengan demikian, tidak semua orang dapat menjadi pengawas BK dan melakukan proses pengawasan BK. Sehingga hal ini terbukti bahwa pelaksanaan supervisi bimbingan dan konseling yang terjadi bukan dari orang yang ahli dan kompeten dalam bidang tersebut melainkan pelaksanaan supervisi dilakukan oleh kepala sekolah atau pengawas yang notabennya bukan dari Bimbingan dan Konseling.

\section{Kompetensi Supervisor}

Dari sudut pandang etika dan hukum, pengawas harus memiliki pendidikan dan pelatihan untuk menjalankan peran mereka secara memadai. Undang-undang lisensi konselor di sejumlah negara bagian sekarang menetapkan bahwa konselor profesional berlisensi yang mempraktikkan supervisi diharuskan memiliki pengalaman pelatihan yang relevan dan kursus kerja dalam pengawasan. Peran pengawasan membutuhkan banyak keterampilan dan nilai yang berbeda dari hubungan terapeutik. Beberapa atribut pribadi yang secara konsisten diidentifikasi sebagai membantu dalam supervisor termasuk empati, rasa hormat, keaslian, kehangatan pribadi, sikap suportif, kemampuan untuk menghadapi, kesegeraan, perhatian untuk mengawasi pertumbuhan dan kesejahteraan, perhatian terhadap diri konseli, ketersediaan untuk refleksi diri, fleksibilitas dan keterbukaan terhadap ide-ide baru dan pendekatan terhadap kasus, keberanian, humor, toleransi, dan keterbukaan terhadap berbagai gaya pembelajaran. 
Menurut British Association for Counselling and Psychotherapy (BAC) (Wheeler \& King. 2001), kompetensi supervisor membutuhkan keterampilan dan pengetahuan yang dapat digunakan untuk menyediakan layanan kepada konseli. Sehingga supervisor harus memiliki keahlian yang memadai yang diperoleh melalui pelatihan atau pengalaman. Selain itu, supervisor akan mencontohkan praktik baik tingkat tinggi untuk pekerjaan yang mereka awasi, terutama berkenaan dengan tingkat kompetensi dan profesionalisme yang diharapkan, membangun hubungan, pengelolaan batas pribadi, hubungan ganda apa pun, konflik kepentingan dan menghindari eksploitasi.

Masalah dalam pengawasan dan konsultasi serta teori dan praktik dalam pelayanan bimbingan dan konseling masih sangat dirasakan oleh guru Bimbingan dan Konseling. Terbukti bahwa pelaksanaan supervisi bimbingan dan konseling yang terjadi bukan dari orang yang ahli dan kompeten dalam bidang tersebut melainkan pelaksanaan supervisi dilakukan oleh kepala sekolah ataupun pengawas yang notabene bukan dari Bimbingan dan Konseling. Seorang supervisor selain sudah mendapatkan pelatihan khusus dalam metode pengawasan, supervisor juga harus memiliki pengetahuan mendalam tentang bidang khusus di mana mereka akan memberikan pengawasan, sehingga tidak etis bagi supervisor untuk menawarkan pengawasan di area yang berada di luar cakupan praktik, walaupun supervisor memiliki kompetensi terkait dengan kualitas pribadinya.

Supervisor yang baik setidaknya memiliki empat nilai yaitu mereka cenderung tersedia, dapat diakses, ramah dan mampu. Dengan demikian, supervisor yang tidak secara efketif menjalankan peran supervisor akan membahayakan peserta pelatihan atau guru Bimbingan dan Konseling yang menjadi trainee, sehingga tujuan utama pengawasan kurang terlaksana dengan baik yang dapat mengakibatkan kurangnya keterampilan dan perkembangan guru Bimbingan dan Konseling.

\section{Kesimpulan}

Dalam supervisi guru bimbingan dan konseling atau konselor terbukti efektif dapat meningkatkan keterampilan, pemahaman guru bimbingan konseling dan mampu dalam meningkatkan penguasaan praktek konseling. Dimana dengan diterapkannya supervisi bimbingan konseling yang dilakukan supervisor dapat membantu guru bimbingan konseling untuk meningkatkan dan lebih mengembangkan skill dalam keterampilan layanan bimbingan konseling. Peran pengawas membutuhkan banyak keterampilan dan nilai yang berbeda dari hubungan terapeutik. Pengawas harus memiliki pendidikan dan pelatihan untuk menjalankan peran mereka agar guru bimbingan konseling/konselor menerima umpan balik secara teratur sehingga mereka memiliki dasar untuk mengasah keterampilan mereka.

\section{Saran}

Untuk penelitian berikutnya perlu dilakukan kajian lebih mendalam lagi dan meninjau dari aspek lainnya yang belum di bahas dipenelitian terdahulu sehingga lebih memperkuat hasil penelitian yang sudah ada.

\section{Daftar Pustaka}

Amelisa, Maya. (2019). "Supervise Bimbingan Dan Konseling Dalam Meningkatkan Penguasaan Keterampilan Layanan Konseling Guru BK." doi: 10.31219/osf.io/gc2rp.

Corey, G., Corey, M.S., Callanan, P. (2011). Issues and Ethics in the Helping Professions Eighth Edition. USA: Brooks/Cole, Cengage Learning. 
European Association For Counseling. (2014). Counseling Supervision. https://eac.eu.com/membership-applications/about-european-eac/

Farid Mashudi. (2013). Panduan evaluasi dan bimbingan konseling, Yogyakarta: Diva press

Handika, M., \& Herdi, H. (2021). Efektivitas Layanan E-Counseling dalam Membantu Permasalahan Siswa Selama Masa Pandemi Covid-19. Jurnal Paedagogy, 8(4), 506511. doi:https://doi.org/10.33394/jp.v8i4.3948

Jasmani \& Syaiful Mustofa. (2013). Supervisi Pendidikan. Terobosan Baru dalam Peningkatan Kinerja Pengawas Sekolah dan Guru. Jogjakarta: Ar-Ruzz Media.

Noverta, Widiyati. (2019). "Supervise Bimbingan dan Konseling Dalam Meningkatkan Penguasaan Keterampilan Layanan Konseling Guru BK.” Jurnal Supervisi Pendidikan.

Partowisastro, Koestoer. (1982). Bimbingan dan Penyuluhan di Sekolah. Jakarta: IKIP. Erlangga.

Sari, M., \& Herdi, H. (2021). Cyber Counseling : Solusi Konseling di Masa Pandemi. Jurnal Paedagogy, 8(4), 579-585. doi:https://doi.org/10.33394/jp.v8i4.3949

Wiratna Sujarweni. (2014). Metodeologi Penelitian Yogyakarta: Pustaka Baru Perss

Wheeler, S., \& King, D. (2001). Supervising Counsellors. Issues of Responsibility. London: Sage Publications.

Wiles, Kimball dan Jhon T. Lovell. (1967). Supervision for Better School, (New Yersey: Prentice-Hall, Inc. Inglewood-Cliffs 